Supplement of Atmos. Chem. Phys., 17, 993-1015, 2017

http://www.atmos-chem-phys.net/17/993/2017/

doi:10.5194/acp-17-993-2017-supplement

(C) Author(s) 2017. CC Attribution 3.0 License.

(c) (1)

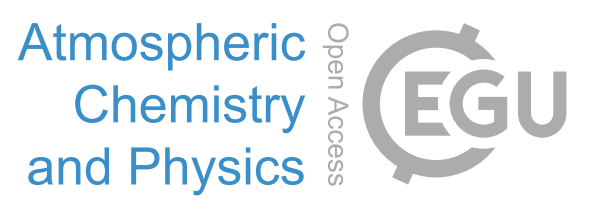

Supplement of

\title{
Quantifying local-scale dust emission from the Arabian Red Sea coastal plain
}

\author{
Anatolii Anisimov et al. \\ Correspondence to: Georgiy Stenchikov (georgiy.stenchikov@kaust.edu.sa)
}

The copyright of individual parts of the supplement might differ from the CC-BY 3.0 licence. 


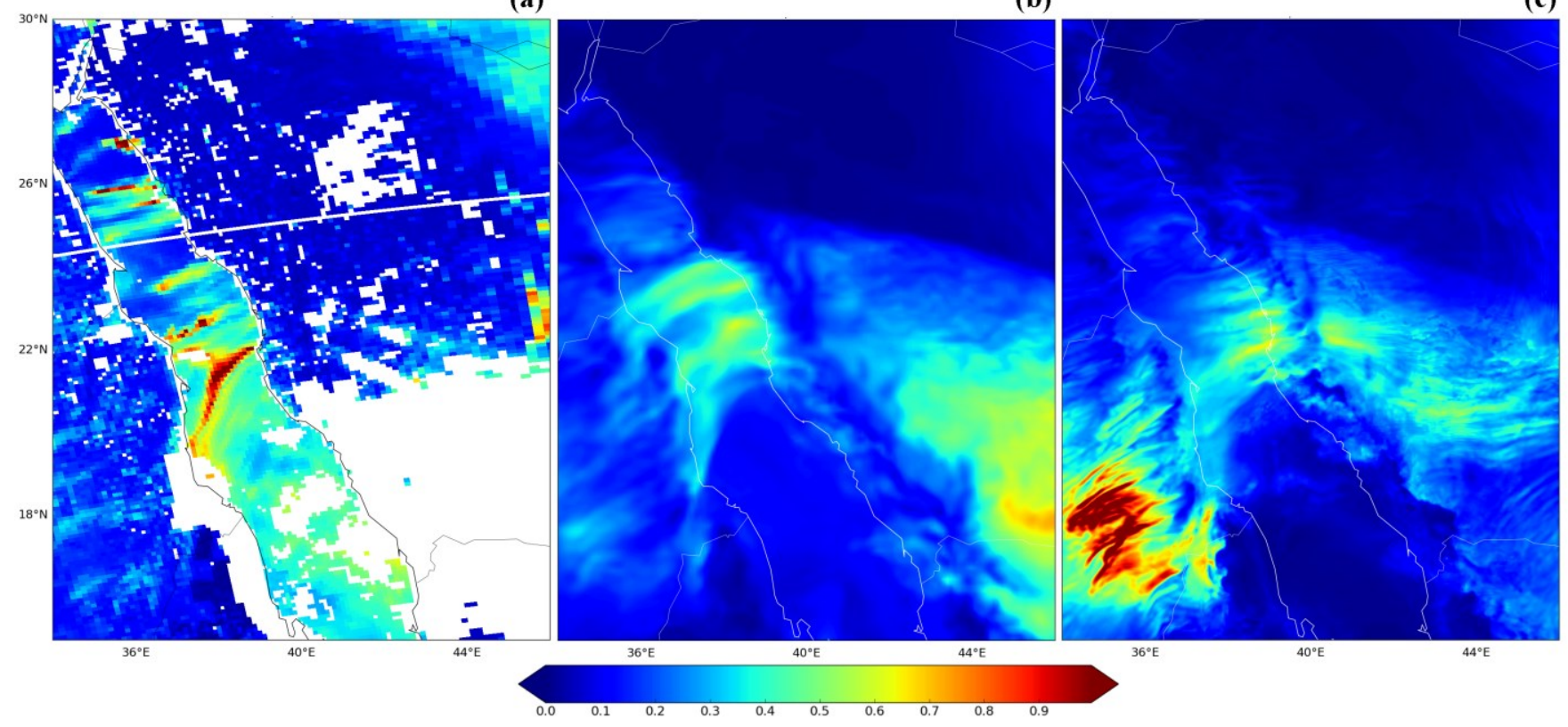

Figure S1. Aerosol optical depth (AOD) from (a) MODIS AQUA satellite (MYD04_L2 collection 6 combined Dark Target (ocean and dark land) and Deep Blue (bright land) product) at 10.55 UTC on 14 January 2009; (b) Kalenderski et al. (2013) WRF-Chem simulation at 11.00 UTC on 14 January 2009; (c) current study WRF-Chem simulation at 11.00 UTC on 14 January 2009. 
(a)

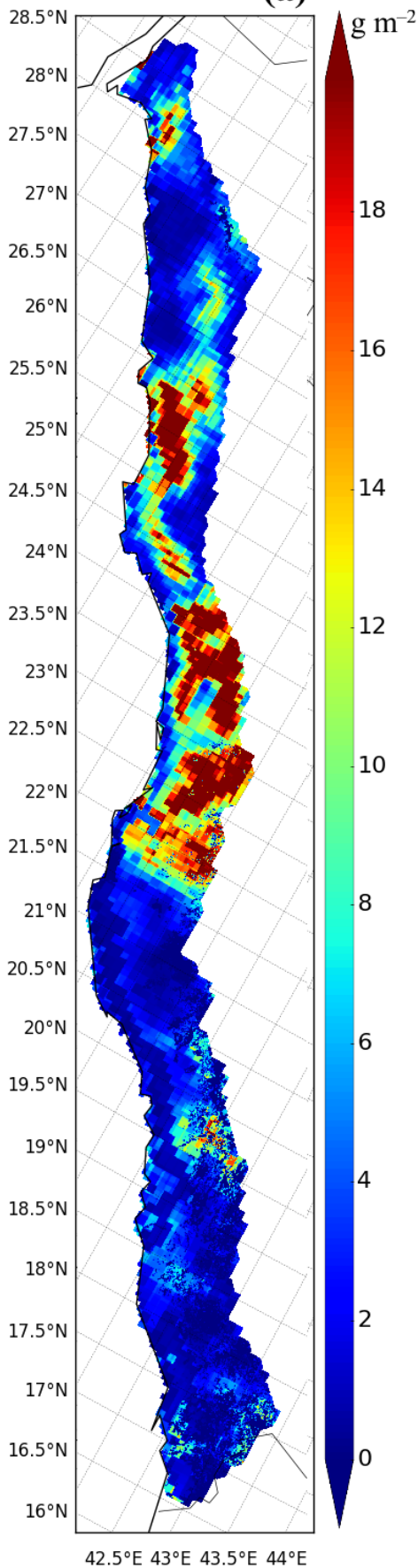

(b)

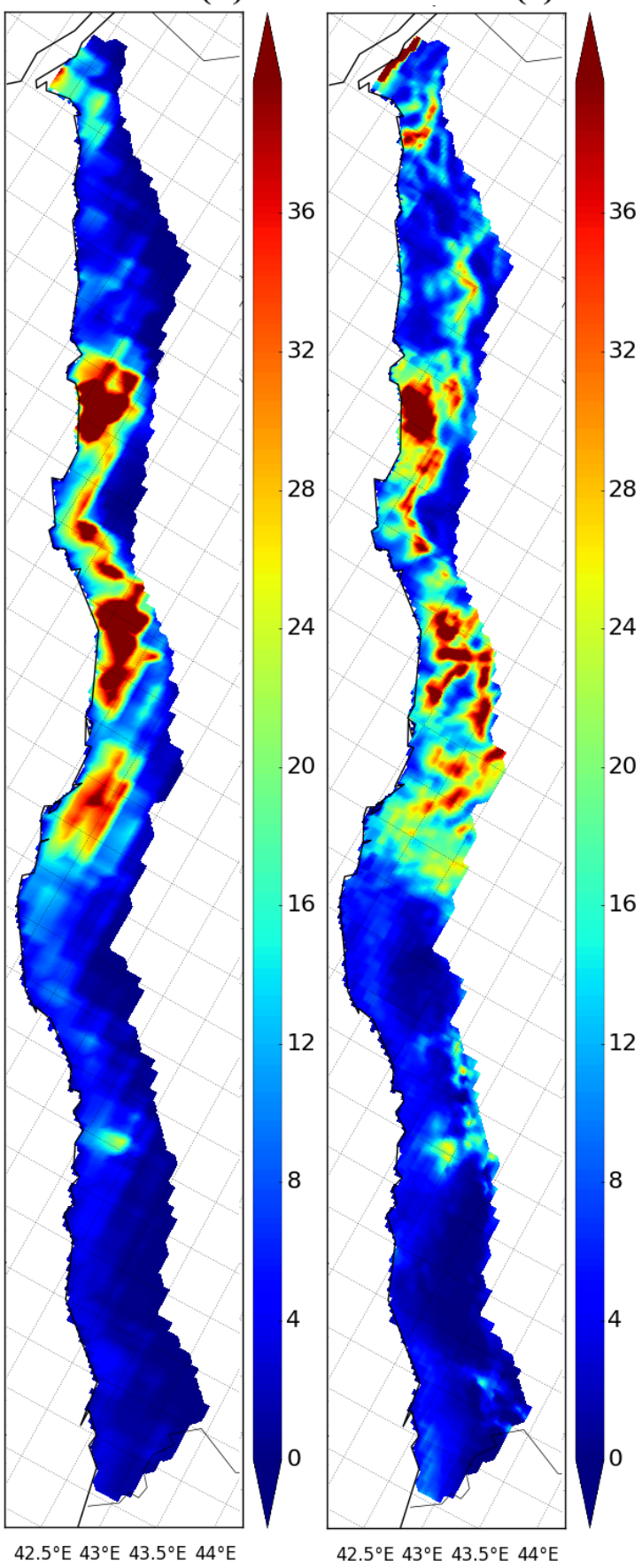

Figure S2. Dust emission $\left(\mathrm{g} \mathrm{m}^{-2}\right.$ ) in (a) $1 \mathrm{kmALL}$ experiment with SEVIRI source function during 1-31 January 2009; (b) Kalenderski et al. (2013) WRF-Chem simulation during 1-20 January 2009; (c) current study WRF-Chem simulation during 1-31 January 2009. 